\title{
O bituario
}

\section{Dr. Werner Roeschmann von Bischoffshausen}

\author{
Werner Roeschmann von B, M.D.
}

$\mathrm{C}$ on profundo pesar hemos recibido la noticia del fallecimiento del Dr. Werner Roeschmann von Bischoffshausen, ocurrido en Santiago el 22 de abril pasado. El Dr. Roeschmann estuvo ligado estrechamente a la Sociedad Médica de Santiago y, en particular, a la Revista Médica de Chile, su órgano oficial. Nacido en Chillán en 1914, cursó sus estudios en el Colegio Alemán y, luego, en la Facultad de Medicina de la Universidad de Chile, obteniendo el título de Médico-Cirujano en 1940. $\mathrm{Su}$ tesis de título versó sobre «studio del urobilinógeno fecal en las enfermedades hepatobiliares». El Internado lo realizó en la Cátedra de Medicina del Profesor Dr. Hernán Alessandri Rodríguez, en el Hospital del Salvador de Santiago. Una vez graduado, se incorporó al Servicio de Medicina del mismo hospital, donde se desempeñó hasta su jubilación como médico internista y gastroenterólogo y ayudante de la cátedra universitaria. Además, ejerció activamente la medicina privada. Integrante del grupo de Hepatología, tuvo bajo su responsabilidad durante muchos años el tratamiento anticoagulante de los pacientes de todo el hospital, en una época en que se introducía tímida y cautelosamente este tipo de terapia en nuestro país.

En otra faceta destacada de su vida profesional, el Dr. Roeschmann se vinculó tempranamente con la Revista Médica de Chile. Así, poco después de graduarse se incorporó a ella como Secretario del Comité de Redacción, cargo que ejerció en 1941 y 1942. Al año siguiente, se integró a dicho Comité siendo uno de sus miembros por casi

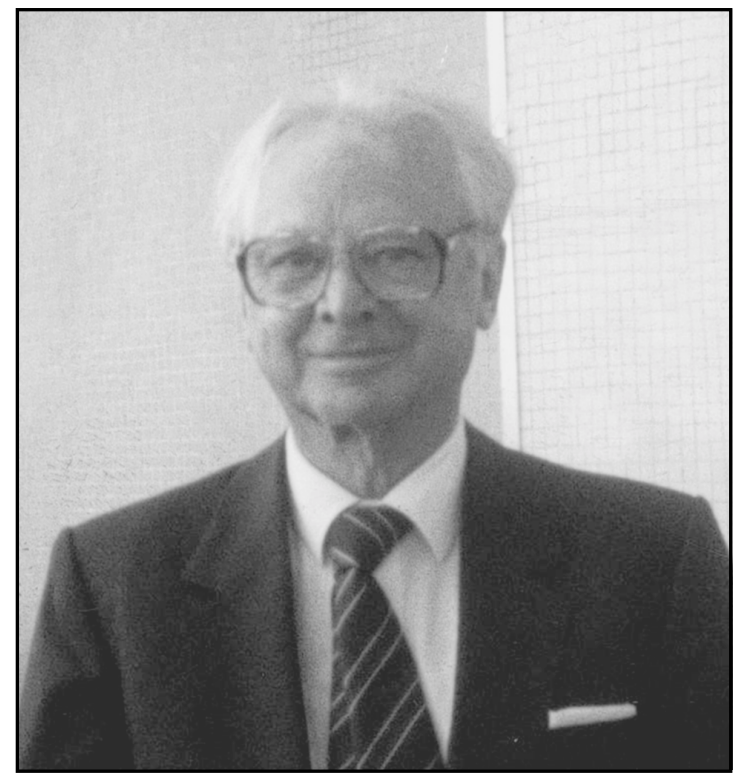

Dr. Werner Roeschmann von Bischoffshausen 1914-2007

veinte años. Durante ese período fueron Directores de la Revista, sucesivamente, los Drs. Renato Gazmuri, Enrique Montero y José Barzelatto. En 1963, fue designado por la Sociedad Médica de Santiago como Director-Editor de la Revista Médica de Chile, función que desempeñó hasta 1969. $\mathrm{Al}$ incorporarme como miembro del Comité Editorial de la Revista en 1966, aprendí de él las complejidades del proceso editorial y las dificulta- 
des inherentes a la publicación de una revista médica periódica en nuestro país.

Al Dr. Werner Roeschmann le correspondió dirigir la Revista en una época particularmente complicada en que la oferta de trabajos para su publicación era relativamente baja, dado que la productividad científica en el área clínica lo era. En esos años, se estaba produciendo un cambio relevante en la medicina nacional: se consolidaban las subespecialidades de la Medicina Interna y surgía paulatinamente una nueva generación de clínicos que asumían la investigación como una tarea importante de su actividad profesional, especialmente los que estaban vinculados a la vida universitaria. Además, debió enfrentar dificultades económicas para el financiamiento de la Revista. Roeschmann asumió su tarea con dedicación y entusiasmo ejemplares, manteniendo la regularidad en su publicación mensual y esforzándose por hacerla progresar y acrecentar su prestigio. En la época en que la dirigió, no se contaba con los medios electrónicos que hoy día facilitan enormemente la recolección de información, la preparación de los artículos científicos y el proceso editorial. Recuerdo, entre otras de sus iniciativas, la preparación del Índice Anual de la Revista Médica de Chile que realizaba en forma manual, registrando personalmente en pequeñas tarjetas los trabajos publicados, las que luego ordenaba metódicamente por materias y autores. Un trabajo que hoy se realiza computacionalmente con facilidad y rapidez, en aquel tiempo era arduo y tedioso. Además, corregía meticulosamente las figuras antes de enviarlas a la imprenta, para lo cual en una oficina de la Revista hizo instalar una mesa de dibujo y rehizo muchas figuras, usando pantógrafo, en papel mantequilla y con tinta china negra, a lo cual agregaba paciencia y entusiasmo.

El Dr. Roeschmann era casado con la Sra. Ana Stanley P., con quien tuvo tres hijos: Silvia, Roberto y Mónica, y diez nietos. Era una persona afable y tranquila, sin ambiciones ni afanes de figuración, que contaba con la simpatía de sus colegas, amigos y colaboradores. Aficionado al golf, perteneció al Club Deportivo Manquehue, al Prince of Wales Country Club y al Club de Golf de Santo Domingo, y ejerció la presidencia de la Asociación de Golf Senior de Chile. A los 88 años de edad, en canchas del Prince of Wales Country Club, hizo hoyo en 1», hazaña que -por su edad- lo convirtió en postulante a aparecer en el Libro de Records de Guinness. Además, era miembro de la Liga Chileno-Alemana de Cultura. La Sociedad Médica de Santiago, en reconocimiento a sus méritos profesionales lo nombró Miembro Honorario.

Junto con asociamos al duelo que aflige a su distinguida familia, los médicos que hemos estado vinculados directamente con la Revista Médica de Chile, a la que el Dr. Werner Roeschmann dedicó muchos años de su vida y le prestó señalados servicios, lo recordamos hoy con respeto y afecto.

\section{Dr. Alejandro Goic G.}

Editor Emérito de la Revista Médica de Chile 